\title{
Crisis, valor y esperanza: repensar la economía
}

(4) Susana Narotzky ${ }^{1}$ Niko Besnier ${ }^{2}$

\author{
1 Universidad de Barcelona, Barcelona, España \\ ORCiD: 0000-0001-7390-7840 \\ Correo electrónico: narotzky@ub.edu \\ 2 Universidad de Ámsterdam, Ámsterdam, Países Bajos \\ ORCiD: 00oo-0001-6046-3494 \\ Correo electrónico: n.besnier@uva.nl
}

doi: $10.34096 /$ cas.i51.8236

Nota de los editores: Artículo traducido y revisado a partir del original publicado en la Revista Current Anthropology, 55 no. S9 (August 2014): S4-S16. Traducción: Ayelén Arcos y Belén Santín Ruffo. Supervisión: Sandra Wolanski. Versión revisada por los autores.

\section{Palabras clave}

Economía; Reproducción social; Crisis; Valor; Escala

\section{Crisis, Value, and Hope: rethinking the Economy}

\author{
Abstract \\ Crisis, value, and hope are three concepts whose intersection and mutual constitution \\ open the door for a rethinking of the nature of economic life away from abstract models \\ divorced from the everyday realities of ordinary people, the inadequacies of which \\ the current world economic crisis has exposed in particularly dramatic fashion. This
}

\section{Key words}

Economy; Social reproduction; Crisis; Value; Scales 
rethinking seeks to bring to center stage the complex ways in which people attempt to make life worth living for themselves and for future generations, involving not only waged labor but also structures of provisioning, investments in social relations, relations of trust and care, and a multitude of other forms of social action that mainstream economic models generally consider trivial, marginal, and often counterproductive. A holistic understanding of how people organize their economic lives is attentive to both the temporality of value and the relationship between different scales of value. It is attentive to the spatial configuration of economic life in many societies in which the future has become synonymous with geographical mobility. Also to the fact that making a living is about making people in their physical, social, spiritual, affective, and intellectual dimensions.

\section{Crise, valor e esperança: repensando a economia}

\section{Resumo}

Palavras-chave

Economia; Reprodução social; Crise; Valor; Escalas

1. N. del T. Traducimos el término en inglés "value" como

"valor" o "valor de cambio" cuando corresponda. En el caso del término "worth", para el cual no existe un equivalente literal en español, acompañamos la traducción al español con una aclaración del término en inglés.
Crise, valor e esperança são três conceitos cuja interseção e constituição mútua abrem as portas para repensar a natureza da vida econômica, afastando-se de modelos abstratos divorciados da realidade cotidiana das pessoas comuns, cujas inadequações foram expostas pela atual crise econômica mundial de maneira particularmente dramática. Estse repensar procura trazer ao centro das atenções as maneiras complexas pelas quais as pessoas tentam tornar a vida digna de ser vivida para si e para as gerações futuras, envolvendo não apenas o trabalho assalariado, mas também as estruturas de aprovisionamento, investimentos em relações sociais, relações de confiança e cuidado, e uma infinidade de outras formas de ação social que os modelos econômicos dominantes geralmente consideram triviais, marginais e frequentemente contraproducentes. Uma compreensão holística de como as pessoas organizam suas vidas econômicas está atenta à temporalidade do valor e à relação entre diferentes escalas de valor. Está atenta à configuração espacial da vida econômica em muitas sociedades nas quais o futuro se tornou sinônimo de mobilidade geográfica. Ela está atenta ao fato de que ganhar a vida significa produzir pessoas em suas dimensões física, social, espiritual, afetiva e intelectual.

Repensar la economía es un proyecto ambicioso, y la selección de los tres conceptos de crisis, valor y esperanza busca desplegar un debate más amplio cuyo punto de partida son las "crudas" realidades de las mayorías, de las personas comunes. Colocando allí el foco, intentamos reflejar el hecho de que -aun cuando sus capacidades de toma de decisiones se encuentran restringidas por recursos limitados, en términos de riqueza o poder- las personas comunes y corrientes pueden desarrollar complejas estrategias individuales y/o colectivas para mejorar su bienestar individual y el de las generaciones futuras. Aquí definimos "bienestar" como el logro de expectativas socialmente razonables de comodidad material y emocional, que dependen del acceso a los diversos recursos necesarios para alcanzarlas. La crisis global ha producido en muchas regiones del mundo un contexto de ruptura de las expectativas, y ocasionó la reconfiguración de los valores ${ }^{1}$ y la reorganización de los marcos de obligación moral. Como resultado, la imaginación de futuros posibles y de los modos para alcanzarlos también han cambiado. En este sentido, los trabajos que reunimos aquí combinan y entrelazan diversos interrogantes en torno a la cuestión central de "ganarse la vida". 
Los tres conceptos interrelacionados de crisis, valor y esperanza sostienen una perspectiva metodológica en la que se destaca el análisis de escala, a la vez que hacen foco en las prácticas y comprensiones de la vida diaria. "Crisis" refiere a aquellos procesos estructurales que generalmente son entendidos como por fuera del control de las personas, pero que a la vez expresan su pérdida de confianza en los elementos que les proporcionaban una relativa estabilidad sistémica y expectativas razonables para el futuro. "Valor" indica un terreno en el que las personas negocian los límites que definen lo socialmente valioso (worth), y opera en la intersección entre los marcos institucionales y normativos "de arriba abajo" y los significados y obligaciones colectivas "de abajo arriba". Finalmente, "esperanza" señala la tensión entre las expectativas personales, la capacidad para diseñar proyectos y la posibilidad real de llevarlos a cabo en una coyuntura determinada. Queremos privilegiar una perspectiva desde "la base de la pirámide", centrada en las prácticas cotidianas que la mayoría de las personas comunes realizan para ganarse la vida. Sin embargo, el uso de la escala como método sitúa inmediatamente nuestra investigación en un campo de conexiones con otros actores sociales, a saber, aquellos que acumulan riqueza, conocimiento y poder, y que pueden operar a escalas institucionales y de amplio alcance.

Nuestro objetivo es desarrollar una teoría de la reproducción social del capitalismo actual, pero creemos que esto solo es posible si se entiende que la separación entre el modelo abstracto y sus manifestaciones concretas es en sí misma un aspecto de la ideología económica dominante que debemos abordar críticamente. En este sentido, las constelaciones específicas de relaciones sociales y disposiciones culturales que producen el tejido de la vida cotidiana se vuelven, en sus conexiones mutuas, estructuralmente significativas para la acumulación capitalista. Producidas históricamente, las especificidades regionales y locales de las formas en que se integran las prácticas económicas son decisivas en un proceso complejo que articula una multiplicidad de actores sociales y disposiciones institucionales en un espacio global de acumulación. Sostenemos que la etnografía es un instrumento privilegiado para abordar la producción histórica de esa especificidad y su papel en la estructuración de la diferenciación.

Las formas en que las personas se ganan la vida en diferentes contextos sociales y culturales constituyen un campo de interés de larga data para la antropología. Durante décadas, las y los antropólogos han generado un gran corpus de materiales etnográficos que documentan la diversidad de prácticas y razonamientos que están implicados en el ganarse la vida en diferentes situaciones. El tema ha sido abordado en distintos momentos de la historia de la disciplina a partir de diversas perspectivas teóricas y metodológicas. Un conjunto de antropólogos (Wolf, 1982; Mintz, 1986; Roseberry, 1988) centraron su análisis en las condiciones materiales y las relaciones sociales que hacen posible la producción (por ejemplo, el acceso a recursos, la propiedad), mientras que otros han colocado el énfasis en la circulación de recursos y en los marcos de obligaciones que movilizan las transferencias y definen la asignación diferencial de recursos (por ejemplo, el don, la mercancía) (Malinowski, 1961a, 1961b; Gregory 1982, 1997). No obstante, trabajos recientes han tendido a abordar producción y circulación como inextricablemente vinculadas entre sí en la práctica social.

En un contexto de gradual expansión mundial del sistema de mercado en tanto que modo dominante de distribución de los recursos, el intercambio se ha impuesto a la vez como concepto y como preocupación antropológica. Además, la creciente preeminencia que adquirió la ciencia económica en el transcurso del siglo XX -como disciplina científica cuyo objetivo principal es la creación de modelos de coordinación de mercado basados en la posibilidad del cálculo- ha contribuido a que el principio de mercado se convirtiera en una poderosa metonimia de la economía misma. Esto se ha visto facilitado por la expansión de los principios de mercado a la mayoría de 
los dominios sociales y áreas del mundo. De esta manera, el intercambio y el cálculo se han convertido en temas que las y los antropólogos han tenido que abordar para conceptualizar el valor y los procesos de valoración.

El interés antropológico por el intercambio se remonta al período fundacional de la disciplina, particularmente a las obras de Malinowski (1961a, 1961b) y Mauss (2003), y ha dado lugar a importantes debates en torno al valor. Algunos de los más prolíficos trabajos del último medio siglo se han centrado en el reconocimiento de que, en su vida cotidiana, las personas se involucran simultáneamente en diferentes "esferas" o "regímenes" de valor (Bohannan, 1959; Appadurai, 1988a y b; Bloch y Parry, 1989). Un aspecto importante de lo que hace que algo sea valioso es su capacidad para preservar, aumentar o transformar su valor social (worth) a medida que se mueve en el tiempo y el espacio (Munn, 1992; Graeber, 2001), lo que a menudo implica alterar las escalas de valor existentes, o construirlas en formas complejas (Thomas, 1991; Guyer, 2004; Besnier, 2011). Aquí, sin embargo, buscamos ir más allá del intercambio como paradigma principal. En efecto, investigamos la economía poniendo el foco en la reproducción social, es decir, en las continuidades y las transformaciones de los sistemas colectivos que sustentan la vida.

\section{Ganarse la vida}

Nuestro objetivo principal es contribuir a repensar la economía desde la riqueza del conocimiento antropológico -tanto empírico como teórico- que ha documentado las prácticas para ganarse la vida en diferentes partes del mundo. En particular, nos interesamos por aquello que las personas comunes entienden como "una vida que vale la pena vivir" y lo que hacen para alcanzar ese propósito, especialmente en condiciones de incertidumbre radical ("crisis"). Nuestro énfasis en la investigación etnográficamente fundada tiene como objetivo comparar sociológica y culturalmente aquello que emerge como valioso en distintos casos etnográficos ("valor"). Finalmente, recentramos la comprensión de la economía en torno a la reproducción social, esto es, a las posibilidades objetivas y subjetivas de las personas para proyectar su vida en el futuro ("esperanza").

La reproducción social implica abordar las diferentes escalas en términos de las cuales las personas evalúan la posibilidad de continuidades, transformaciones o bloqueos. Por ejemplo, las y los residentes de la Sarajevo de posguerra son plenamente conscientes de la falta de "progreso" en su existencia actual, teñida por los múltiples obstáculos en el "camino hacia Europa", en contraste con la realización de expectativas "normales" y la esperanza de un futuro mejor de preguerra, un contraste que proyecta el futuro en diferentes escalas en cada caso (Jansen, 2014). La reproducción social es selectiva, y para comprenderla debemos lidiar con las definiciones de lo que necesita ser reproducido, categorías cuyos límites son el resultado de negociaciones sociales. Lo que nos lleva a centrarnos en la reproducción social es el hecho de que la angustia de las personas sobre sus medios de vida se expresa generalmente en términos de relaciones entre generaciones, ya sea a nivel individual y doméstico (“¿Encontrarán mis hijos un trabajo? ¿Podré formar una familia?”), como a nivel estatal (los jóvenes de hoy como una "generación perdida"). La recurrencia de estos temas pone de manifiesto la importancia de la dimensión espacio-temporal en la forma en que las personas razonan sobre el bienestar y su realización. Las experiencias pasadas proporcionan un horizonte de expectativas que configura las aspiraciones presentes y las esperanzas cara al futuro.

Proponemos repensar las prácticas para ganarse la vida, su materialidad y los conceptos que contribuyen a producirlas formulando los siguientes interrogantes: “¿De qué maneras las experiencias de las personas comunes dan forma a los proyectos de vida que emprenden?" y “¿cómo las realidades materiales, sociales, y culturales constriñen estos 
proyectos?". Proponemos no pensar "la economía" como un dominio de investigación reificado y aislado del resto de la existencia humana, ni como una forma particular de acción social como el cálculo. Más bien, conceptualizamos la economía en sentido amplio, es decir, a partir de todos los procesos que están involucrados, de una manera u otra, en "ganarse la vida", haciendo énfasis tanto en el "esfuerzo" que implica como en el objetivo de "sostener la vida". Pero "ganarse la vida" también tiene que ver con la cooperación y con formar parte de colectivos que dan sentido a una vida que "valga la pena". Si bien concordamos con la reinterpretación de Graeber de la teoría del valor trabajo -que define al valor como el gasto de energía creativa en la producción y el mantenimiento de la sociedad (Graeber, 2001, p. 68)-, también subrayamos la perspectiva, presente en numerosas descripciones etnográficas, de que la forma en que una sociedad representa el valor social (worth) de las personas es una clara expresión de su organización económica y política (Terradas, 1992; Wolf, 1999). Por lo tanto, debemos comprender cuáles son las diferencias significativas (límites, instituciones, categorías de personas) que quienes están en el poder se esfuerzan por reproducir para mantener su valor social (worth) y su riqueza.

Esta comprensión "en sentido amplio" de la economía atraviesa una amplia gama de actividades humanas más allá de lo puramente material, y atiende a la coexistencia entre distintos regímenes de valor. Ganarse la vida no solo depende de que las personas participen en el mercado vendiendo su fuerza de trabajo a cambio de un salario $-o$, de manera alternativa, vendiendo sus productos o servicios fuera de los marcos de regulación estatales, utilizando el financiamiento de microcrédito, o solicitando subsidios al Estado o a alguna ONG-. También implica dinámicas que no son comúnmente consideradas como "económicas" o que a menudo son definidas por la economía convencional como inadecuadas, deficientes o como signos de "atraso en el desarrollo". Por ejemplo, el sacrificio entre los luo, para quienes los dominios de la religión y de las lógicas económicas se superponen, forja conexiones entre entidades materiales e inmateriales, $y$ entre fuerzas pasadas $y$ futuras que son fundamentales para la producción de un sentido de pertenencia, esperanza de futuro, y bienestar físico y espiritual a lo largo de las generaciones (Shipton, 2014). Muchos de los recursos de subsistencia se producen y circulan fuera o al margen de las prácticas de mercado, incluso en los escenarios dominados por el mercado en los que viven la mayoría de las personas. Los circuitos de aprovisionamiento siguen caminos impredecibles, que alternan entre formas de valoración mercantilizada y no mercantilizada, dependiendo del marco de oportunidades disponibles, condicionados por instrumentos políticos y regulados por diferentes modalidades de responsabilidad (Besnier, 2011; Narotzky, 2012b). En tiempos de crisis, las personas desarrollan estrategias que les permiten localizar recursos cada vez más difíciles de alcanzar. Estas estrategias incluyen relaciones de confianza y cuidado, economías de afecto, redes de reciprocidad que abarcan recursos tangibles e intangibles, y transferencias materiales y emocionales que están respaldadas por obligaciones morales. Muchas consisten en actividades no reguladas o actividades que no pueden ser reguladas (Hart, 1973; Stack, 1974; Lomnitz, 1975; Smart y Smart, 1993; Humphrey, 2002; Procoli, 2004). Pero estas estrategias también pueden tener el efecto de definir y marginar categorías de personas (por ejemplo, por razones de origen étnico, género o raza) para quienes el acceso a los recursos se verá restringido violentamente (Sider, 1996; Li, 2001; Smith, 2011).

Con el fin de conseguir que la vida merezca ser vivida, las personas invierten en múltiples aspectos de la existencia que, si bien a primera vista parecen tener poca sustancia económica, terminan teniendo consecuencias económicas. A la inversa de los supuestos que subyacen a las políticas de desarrollo -que priorizan el microcrédito y el espíritu emprendedor-, entre los sectores populares, las relaciones sociales a menudo constituyen una "inversión" mucho más segura que la microemprendeduría. Así, los brasileños pobres de la región de Pernambuco afirman que "el dinero es bueno, pero un amigo es 
mejor". En este sentido, mientras que el dinero desaparece tan pronto como se obtiene, en tiempos de necesidad se puede contar con los lazos de amistad (de L'Estoile, 2014). De manera similar, las mujeres de las zonas rurales de Tamil Nadu, que hace mucho que están familiarizadas con una amplia gama de prácticas de préstamo, incluidas aquellas promovidas por los programas de microcrédito, saben que el endeudamiento genera reconocimiento y apoyo (pero también clientelismo político, obligaciones laborales, y vergüenza) a través del amplio entramado social que supone (Guérin, 2014). Mientras, los migrantes latinoamericanos en Barcelona combinan complejas dinámicas de reciprocidad, cuidados mutuos y transacciones financieras para "salir adelante" en circunstancias difíciles (Palomera, 2014). Pero, aunque las personas en condiciones de profunda precariedad son las más hábiles en el desarrollo de complejas estrategias de aprovisionamiento, la frugalidad de los no tan ricos pero no tan pobres también se constituye sobre múltiples y diversos proyectos para sostener la vida. Estas dinámicas han sido extensamente analizadas en el marco de las empresas familiares, emprendedores étnicos y grupos industriales en la mayoría de las regiones del mundo (Blim, 1990; Portes y Sensenbrenner, 1993; Yanagisako, 2002; Smart y Smart, 2005). También han recibido considerable atención analítica en los "países en desarrollo", donde incluso médicos y funcionarios públicos trabajan de noche como taxistas o en sus pequeños emprendimientos para asegurar la base económica familiar, o donde los funcionarios públicos pueden convertirse en prestamistas o en la puerta de acceso a subsidios (Owusu, 2008; Besnier, 2009). De manera similar, en la Sudáfrica pos apartheid, son las nuevas clases medias negras (así como las blancas) las que participan en lo que algunos denominan "préstamos temerarios", que atestiguan el hecho de que estas familias necesitan algo más que el salario que reciben para mantener las prácticas de consumo asociadas a su posición de clase (James, 2014).

Queremos reflexionar sobre "ganarse la vida" sin privilegiar un dominio particular, ya sea un tipo de actividad (el intercambio), una intencionalidad particular de acción (el beneficio), o un proceso de valoración en particular (el cálculo). Queremos enfatizar que las prácticas que definimos como económicas tienen un objetivo significativo, esto es, sostener la vida a lo largo de las generaciones. Si bien nuestra perspectiva puede ser considerada como neosustantivista, preferimos pensarla como realista y resultante de una larga historia intelectual, centrada en la pregunta sobre cómo las personas cooperan o se enfrentan en torno a la voluntad de producir y reproducir sus medios de vida.

Esta perspectiva se posiciona en la intersección de diversas tradiciones teóricas. En primer lugar, la tradición de la economía política en sus variantes neomarxistas y posmarxistas, que ha inspirado a las y los científicos sociales a explicar la distribución desigual de la riqueza a partir del análisis de los procesos históricos que producen las relaciones de producción -de cooperación, de conflicto o de explotación (Roseberry, 1988, 1989)-. Esta tradición -cuya relevancia para la comprensión de la realidad mundial actual no ha disminuido- aborda la reproducción social a través del lente de la dialéctica estructural que produce la diferenciación política y económica (Wolf, 1982; Mintz, 1986; Harvey, 2003).

En segundo lugar, los enfoques teóricos que iluminan las economías morales buscan comprender los marcos de obligaciones y responsabilidades mutuas que hacen aceptable la explotación (al menos por un tiempo) y facilitan que perduren formas particulares de diferenciación socioeconómica (Thompson, 1971, 1993; Scott, 1976; Moore, 1978). Las dimensiones morales de las prácticas económicas han suscitado una creciente atención durante la última década (Sayer, 2000; Edelman, 2005; Fontaine, 2008; Browne, 2009; Fassin, 2009; Robbins, 2009; Hann, 2010), como alternativa a la teoría de la acción racional para la explicación de las motivaciones que guían el comportamiento humano. Sin embargo, queremos señalar que es necesario articular esta visión con aquella de la economía política para que resulte en aportes significativos. De hecho, los momentos 
de disyuntiva entre nuevas prácticas de explotación y marcos de obligación pasados evidencian los aspectos morales de la economía en el momento en que están siendo impugnados por quienes están en el poder.

Finalmente, los enfoques de la economía feminista constituyen una base importante para pensar en la "economía de otra manera". La perspectiva feminista ha revelado que el trabajo no remunerado y la ética del cuidado resultan claves para comprender los procesos económicos más allá de la maximización del interés individual (Elson, 2001; Benería, 2003; McDowell, 2004; Nelson, 2006; Lawson, 2007). Fundamental para el bienestar, el cuidado puede ser provisto dentro o fuera de los circuitos de intercambio del mercado, pero también está enmarcado por la tensión entre amor y dinero (Ferber y Nelson, 1993, 2003; Zelizer, 1997). Las prácticas de cuidado implican una configuración de actores sociales que operan en los sectores doméstico, de mercado, estatal y sin fines de lucro, que forman lo que Razavi (2007) llama el "diamante del cuidado". La interdependencia entre los diversos actores sociales indica que los cambios en las prácticas de cuidado en uno de los sectores (por ejemplo, en el hogar) a menudo están relacionados con cambios en otro sector (por ejemplo, en los servicios estatales). Del mismo modo, el "cuidar" se articula con el "recibir cuidado" a lo largo de las cadenas de cuidado que vinculan a los múltiples actores sociales (Hondagneu-Sotelo, 2001; Parreñas, 2001; Hochschild, 2003; Weber, Gojard y Gramain, 2003; Yeates, 2004). Las teóricas feministas también han problematizado la distribución desigual de los recursos y las responsabilidades en el hogar, su relación con las dinámicas de los ciclos de vida y su articulación con otras desigualdades sociales (Dalla Costa y James, 1975; Hareven, 1977; Hartmann, 1981; Narotzky, 1988). El aporte teórico más importante de la economía feminista ha sido, posiblemente, el de demostrar que las relaciones de dependencia personal (en oposición a la autonomía imaginada del actor racional individual) y el valor emocional son elementos fundamentales para la reproducción social. En las prácticas contemporáneas de ganarse la vida subyace la tensión entre los marcos morales que enfatizan la dependencia y los que ponen de relieve la autonomía.

La articulación de estas tres líneas teóricas responde a la metodología de análisis de escala. Las relaciones de cuidado que se observan en el ámbito doméstico, por ejemplo, son el resultado de marcos generizados de obligación moral en una sociedad particular. Generalmente, estos son producidos como expresiones locales o diaspóricas de movimientos globales de diferenciación social y acumulación de la riqueza, y están sujetos a procesos de institucionalización. Por ejemplo, las y los trabajadores migrantes polacos, provenientes de distintas partes del país y en diferentes períodos, establecen particulares configuraciones de cuidado con familiares y amistades, que están determinadas por los distintos contextos económicos y políticos que influyen en la decisión de migrar (Pine, 2014). De manera similar, las y los trabajadores migrantes mexicanos en California hacen malabarismos entre diferentes regímenes de valor, que se entretejen con las diversas obligaciones para con sus familias en su país de origen, con la necesidad de mostrar que "lo han logrado", con las estructuras políticas y económicas del trabajo y con las políticas migratorias (Villarreal, 2014). En síntesis, mientras que la economía feminista permite recentrar la economía en torno a la necesidad humana de apoyo mutuo, y la economía política presta atención a los movimientos que producen la diferenciación - que facilitan la acumulación de riqueza y su distribución desigual-, la economía moral indaga en las bases para realizar reivindicaciones, los marcos de adjudicación de derechos y el diseño de expectativas razonables.

\section{Crisis}

Los periodos de crisis exponen la fragilidad de las estructuras económicas de manera particularmente dramática. Al mismo tiempo, conducen a las personas -cuando no 
las obligan- a crear nuevos medios de vida y a adaptar los anteriores a condiciones cambiantes. Las crisis indican una ruptura en la reproducción social, un desajuste entre las configuraciones de cooperación que solían funcionar, y producen expectativas y obligaciones particulares y una configuración diferente de oportunidades y recursos. Como concepto, "crisis" une dos significados de distintos órdenes que no tienen resolución.

Las crisis contrastan con las formas de estabilidad que, por un lado, posibilitan el diseño de proyectos y, por el otro, sostienen la confianza en las configuraciones existentes para llevar a cabo la realización de esos proyectos. Frente a esta idea de normalidad, las crisis indican un quiebre que emerge como una amenaza, al mismo tiempo que empuja al ingenio y a la creatividad. Existe una larga historia de pensamiento académico que concibe a las rupturas como períodos limitados en el tiempo que dan paso finalmente a la estabilidad; pensamiento que ha tenido influencia tanto en las comprensiones populares como en las analíticas (Koselleck, 2006). La fe en una estabilidad relativa conseguida por medio de políticas monetarias constituye la base epistemológica que sustenta las predicciones de las corrientes económicas dominantes sobre el futuro. Sin embargo, la realidad observable muestra que las crisis pueden no ser tan excepcionales como asumen las y los economistas, lo que explica por qué se ven en tantos apuros a la hora de justificar sus predicciones fallidas -como lo expuso de manera dramática la crisis económica mundial iniciada en 2008-. Por el contrario, para la teoría marxista, la crisis es una característica inherente al sistema capitalista, en el que el impulso hacia la obtención de rentabilidad resulta en la tendencia decreciente de la tasa de ganancia capitalista, la sobreproducción, la sobrecapacidad y la sobreacumulación. A pesar de su carácter cíclico, estas rupturas se vuelven cada vez más dañinas para la resiliencia del sistema en general, porque conducen al conflicto entre clases a un punto irresoluble que empujaría todo el sistema hacia el colapso. El aspecto de la temporalidad, sin embargo, debe ser atendido tanto en la comprensión popular de las crisis como en la de las y los expertos, ya sea que aparezca expresado como un tiempo discontinuo de puntos de inflexión significativos (Guyer, 2007; Jansen, 2014) o como un tiempo de espera que hay que sobrellevar (de L'Estoile, 2014), ya sea que la ruptura esté situada a nivel subjetivo o del sistema.

De hecho, existe amplia evidencia que sugiere que la inestabilidad y la incertidumbre han sido la norma en la mayoría de los contextos sociales, culturales e históricos. Los períodos de estabilidad, como el momento de crecimiento económico y de expansión del bienestar social que siguió a la Segunda Guerra mundial en América del Norte y Europa ("les trente glorieuses" de Francia) constituyen, de hecho, anomalías históricas, que en todo caso solo beneficiaron a una parte relativamente pequeña de la población mundial, y que se basaron en prácticas extractivas neocoloniales que hicieron la vida más difícil en muchos otros lugares. En la mayoría de las circunstancias, las personas deben lidiar con la imprevisibilidad de sus proyectos, y hacer de la crisis, más que del riesgo, una parte integral de sus horizontes de expectativas. Sin embargo, excepto en circunstancias extremas, las personas crean prácticas e instituciones, a menudo de carácter $a d$ hoc, que amortiguan los efectos de la inestabilidad y permiten un sentido relativo de continuidad a lo largo del tiempo.

Actualmente, una proporción cada vez mayor de la población mundial es incapaz de alcanzar el bienestar o solo lo logra de manera precaria. Al mismo tiempo, mientras las instituciones que regulan los marcos morales y políticos de responsabilidad y sostienen la transferencia de recursos (por ejemplo, el Estado, la familia, la Iglesia) se ven debilitadas de varias maneras, otros marcos institucionales (por ejemplo, religiosos, étnicos, nacionalistas) se crean y reconfiguran para guiar el comportamiento humano y canalizar los bienes. Sin embargo, esta creatividad puede implicar prácticas de exclusión por medio de la construcción y demonización de un Otro (según distintos ejes de desigualdad que incluyen, entre otros, la raza, el género, la etnia, el nacionalismo), 
que se vuelve el blanco de la violencia en las disputas por el acceso a los recursos y el respeto (Hage, 1998; Holmes, 2000; Gingrich, 2006; Kalb, 2009). Estos efectos evidencian la necesidad de comprender el ingenio y la creatividad -así como sus trasfondos potencialmente oscuros- que los sujetos sociales despliegan para hacer frente a una situación en la que tienen que vivir y que, en gran medida, no es de su propia creación.

La actual crisis financiera mundial iniciada en 2008, por ejemplo, ha generado incertidumbre en los antiguos centros capitalistas occidentales, tanto de naturaleza económica (reducción de recursos, disminución de oportunidades de empleo, precarización del trabajo, disminución del crédito, aumento de la tributación indirecta, reducción estatal de beneficios sociales), como de naturaleza política (pérdida de poder, pérdida de derechos, "gobiernos técnicos", déficit democrático), situación que hace tiempo tiene lugar en otras áreas del capitalismo mundial. La incertidumbre afecta a las personas en su capacidad de reproducción material y emocional, que generan dificultades para formar nuevas familias, mantener las existentes, construir relaciones de cuidado y sentirse respetadas. Colocar el foco en las relaciones intergeneracionales -como las que se expresan por medio de las transferencias de activos tangibles e intangibles (por ejemplo, propiedad, cuidado, conocimiento, habilidades y valores)- pone de relieve las complejidades de la reproducción social a diferentes escalas. De hecho, la reproducción social se puede definir como una continuidad que une a las generaciones en torno a microproyectos para ganarse la vida y mejorar sus oportunidades futuras, y macroproyectos de configuraciones sociales de poder y distribución de recursos. Al mismo tiempo, las crisis pueden generar nuevas formas de comprender a las "generaciones", especialmente en lo que respecta a sus implicaciones para la reproducción de la sociedad en su conjunto, más allá de los límites de los grupos privados. En particular, las realidades de las situaciones y el discurso de crisis transforman los contextos materiales y morales en los que se sostienen las transferencias inter e intrageneracionales.

En el sur de Europa, por ejemplo, la crisis se ha convertido en parte de la realidad cotidiana de la gente común, con la que tienen que lidiar las personas en el intento de ganarse la vida y en su deliberación sobre cómo invertir en la próxima generación. Mientras las y los expertos y los gobiernos insisten en que la crisis es una situación excepcional, un intervalo antes de que todo vuelva a la normalidad, para muchas personas alrededor del mundo la experiencia del caos y la inseguridad vital permanente constituye el terreno de juego obligado. Desde nuestro punto de vista, por su presencia abrumadora en la vida de muchas personas en todo el mundo, la crisis -como realidad de experiencia y como categoría conceptual popular y analítica- es un buen lugar para basar una investigación sobre la economía.

\section{Valor}

En su “Ensayo sobre el don”, Mauss (2003) demuestra cómo las diferentes prácticas que generan valor (por ejemplo, jurídicas, religiosas, económicas, estéticas) son valoradas e incorporadas en los objetos de valor. Pero además, su preocupación es entender la equivalencia que se alcanza en el intercambio y, por lo tanto, debe considerar la tensión entre "los valores" (values) y "el valor" (value). Otra tensión que el autor encuentra es la que existe entre el objeto material y las relaciones sociales que este expresa. Etnografías más recientes sostienen que estas tensiones no se resuelven con la expansión de los principios del mercado capitalista. En The Great Transformation, lo que Polanyi (1971) denomina "mercancías ficticias" -es decir, la tierra, las personas y el dinero- están en apariencia desincrustadas (disembedded) de otras relaciones sociales en el proceso de intercambio del mercado, pero esta desincrustación es artificial, ya que en realidad están constituidas al interior de marcos de valor distintos. En su capítulo sobre el fetichismo de la mercancía, Marx (1990) se aproxima a esta cuestión de manera diferente pero 
complementaria: las cosas, las personas y la tierra siempre se insertan en relaciones sociales que las producen como mercancías. Tanto Marx como Polanyi consideran que la transformación de esos valores socialmente incrustados en valor de cambio tiene un efecto negativo para la mayoría de las personas y, en términos más generales, para la reproducción social. Al mismo tiempo, dado que las mercancías se producen mediante relaciones sociales concretas dentro de regímenes de valor particulares, cuando ingresan al mercado, los valores concretos adquiridos en el seno de estos regímenes particulares aumentan su valor de cambio en términos de mercado. Por ejemplo, cuando llega a una galería de Nueva York, la "autenticidad" de una alfombra producida en un pueblo turco como parte de una dote le añade valor de mercado (Spooner, 1988; véase también Villarreal, 2014 sobre la necesidad de proporcionar a las y los turistas en Chiapas una "experiencia auténtica"). En términos más generales, la pregunta es si, y cómo, múltiples valores concretos se cristalizan en un único valor de cambio. Gran parte de esto ha sido abordado por la teoría del intercambio y el debate sobre el don (Damon, 1980; Weiner, 1980, 1992; Gregory, 1982, 1997; Strathern, 1988, 1992; Munn, 1992; Godelier, 1996; Robbins y Akin, 1999; Graeber, 2001; Mauss, 2003), y está vinculado al debate sobre el dinero, las monedas especiales, las escalas de cálculo, las conversiones y el entrelazamiento de las distintas prácticas de valoración (Zelizer, 1997; Hart, 2000; Guyer, 2004; Maurer, 2006).

Las y los antropólogos han subrayado que no todos los valores son conmensurables, lo que significa que no pueden medirse en función de una única medida de valor. Tampoco se determinan siempre en el intercambio. Por ejemplo, Godelier (1996), siguiendo a Weiner, destacó la diferencia entre los valores que son "alienables" a través del don o el intercambio, y los valores "inalienables" que deben ser guardados, y vio en estos últimos la expresión del núcleo fundacional de la sociedad. En su distinción entre la "base" y el "mercado", Gudeman (2008) diferencia entre valor "inconmensurable" (que no puede ser medido) y valor "conmensurable" (que puede medirse). El valor no puede ser medido cuando el "compartir" (por ejemplo, dentro del ámbito doméstico o de la comunidad) es la forma de circulación dominante, que tiene lugar en la base. La necesidad de comparación y evaluación mutua surge en los límites de la base, como reciprocidad o intercambio de mercado (por ejemplo, entre hogares o comunidades). El mercado es el epítome de la conmensurabilidad. Sin embargo, en el mercado pueden combinarse múltiples escalas de valor en gradientes continuos, al tiempo que las personas continúan valorando las cosas en diferentes escalas a partir de lo que Guyer (2004) denomina "performances de intercambio" (pp. 97-98) en referencia al África atlántica. Si bien el cálculo es fundamental para el intercambio, no se agotan ahí las prácticas de valoración. Los juicios de valor (worth) pueden no depender de su clasificación en una escala de valor (value) que produce una cualificación mensurable, pero pueden en cambio descansar en la comparación y en la evaluación por parte de un "actor social razonable", integrado en múltiples -y a menudo incompatibles- regímenes de valor. Además, las cosas pueden compararse de manera "difusa" -así como intercambiarse de manera subóptima- como "suficientemente buenas". Finalmente, lo que no se puede contar, comparar o intercambiar es lo que las personas frecuentemente consideran de mayor valor y esencial para la continuidad del hilo de la vida entre pasado, presente y futuro (Shipton, 2014).

Los desarrollos de la economía ecológica han complejizado aún más el debate. Desde hace unos veinte años, las y los economistas ecológicos han abordado el hecho de que el medio ambiente es un sitio de valores en competencia que se expresan, cada vez más, en abierto conflicto. Diferentes actores sociales producen y valoran un lugar (por ejemplo, como un recurso de subsistencia, como un patrimonio comercializable, como un factor productivo, como un sitio religioso, como un bien estético) en términos de los "bienes" y los "males" que se pueden devengar de su diverso uso. Estos conflictos remiten a la conocida tensión entre valores y valor, que desde hace mucho tiempo ha 
atraído la atención de las y los antropólogos (Albert, 1956; Munch, 1970). Las y los economistas ecológicos, al tratar con la valoración en el marco de conflictos ambientales, rechazan el reduccionismo de la conmensurabilidad, es decir, la reducción del objeto valioso a una única medida de valor. En cambio, reconocen el pluralismo de valores. Insisten en que la inconmensurabilidad no implica necesariamente incomparabilidad, sino una comparabilidad débil, de acuerdo con la cual la elección entre alternativas no se basa en una sola medida de comparación. Incluso, frente a la existencia de valores incompatibles, la valoración puede conducir a los actores sociales razonables a desarrollar juicios prácticos. Mientras que la conmensurabilidad se define en términos de compensación -esto es, en un marco de intercambio-, la comparabilidad no depende de contrapartidas sino de preferencias ancladas en la moralidad. La investigación sobre conflictos ambientales se ha centrado, por un lado, en las posibilidades de aceptar una indemnización por un "mal"; por el otro, en la voluntad de compensar por la preservación de un "bien", como atestiguan los tests de "dispuesto a aceptar-dispuesto a pagar" utilizados en las evaluaciones de impacto o en las decisiones forenses (por ejemplo, Exxon Valdez). La negativa a aceptar una reparación a cualquier precio expresa una preferencia absoluta no negociable, que frecuentemente es sostenida por sólidos argumentos colectivos enfocados en el futuro, ya sean de carácter ético o de otra índole. Para las y los afroamericanos y latinos residentes en el sur del área metropolitana de Los Ángeles, por ejemplo, tener que vivir con aire contaminado no es un precio aceptable a pagar a cambio de la promesa de nuevos empleos, de los que, de todos modos, resultarán excluidos como consecuencia de las prácticas discriminatorias de contratación (Brodkin, 2014). De hecho, para compensar la destrucción de ciertos valores, estos deben reducirse a un cierto estándar de valor que posibilite el intercambio de un efecto negativo por un bien equivalente (por ejemplo, una indemnización monetaria, mejoras comunitarias, la promesa de empleos). Si bien la compensación se basa en el cálculo dentro de un marco de intercambio, el valor no siempre es función del cálculo (Funtowicz y Ravetz, 1994; Martínez-Alier, Monda O’Neill, 1998; Spash, 2000). De hecho, desde una perspectiva antropológica, Paige West (2005) nos advierte que los procesos indígenas que dan valor al medio ambiente son a menudo relaciones dialécticas que producen simultáneamente identidad y espacio. Aquí, los procesos de valoración en sí mismos son inconmensurables con respecto al sistema de categorización que sustenta los modelos económicos conservacionistas. "No es que los Gimi valoren los bosques, las plantas y los animales de manera diferente a los forasteros, ellos no necesariamente los 'valoran' en absoluto, porque los Gimi no se separan a sí mismos de su entorno" (West, 2005, p. 639). En Wukan, un pueblo de pescadores en el este de la provincia de Guangdong, las protestas contra el acaparamiento de tierras analizadas por He y Xue (2014) no se basan en una identidad colectiva como campesinos desposeídos, sino que se fundan en distintas agendas que, en conjunto, generan una identidad campesina definida en negativo y crecientemente marginalizada, legitimada por una estructura de clanes reconstituida que reúne elementos anteriores a 1949 con formas locales de Estado (cf. Brandtstädter, 2003).

El dinero desempeña un papel central en la relación entre el cálculo de valor y la moralidad (Bloch y Parry, 1989; Gregory, 1997; Zelizer, 1997; Hart, 2000; Guyer, 2004). Puede ser un instrumento de deseo individual, que impulsa la imaginación sobre la autonomía y la valía personal, tanto como un instrumento de dependencia colectiva, que evidencia cuánto nos pertenecemos los unos a los otros necesariamente (Hart, 2000; Graeber, 2011). El dinero permite llevar un registro de lo que las personas se hacen unas a otras y es, por ello, un instrumento de memoria colectiva. Su capacidad para convertirse en un "banco de memoria" se basa en su habilidad para mantener y, por lo tanto, transmitir valor a lo largo del tiempo. Y este valor alude centralmente a "producir sociedad", y mantenerla viva en el tiempo. Estas dinámicas son especialmente llamativas en el caso de otros tipos de objetos valiosos, como el wampum entre los iroqueses y los objetos de valor melanesios (Munn, 1992; Graeber, 2001). De esta 
manera, la reproducción social vuelve a un primer plano, cuando el dinero es interpretado como un puente que intermedia entre lo individual y lo colectivo, la autonomía y la dependencia, los órdenes transaccionales a corto y a largo plazo. El dinero comparte su capacidad de ser una "reserva de valor" con otros tipos de objetos valiosos, tales como los bienes raíces, que ponen de manifiesto la temporalidad del valor y los criterios que son utilizados para establecer el valor (worth) a lo largo del tiempo. Ello queda demostrado en el atractivo de la vivienda propia como estrategia de ahorro e inversión entre migrantes latinoamericanos en Barcelona, que se materializó en los años 2000 gracias a las hipotecas de alto riesgo, al sobreendeudamiento y a complejas obligaciones de reciprocidad (Palomera, 2014).

La temporalidad del valor resulta particularmente sugerente. En los artículos reunidos en el número especial de la revista Current Anthropology (Vol 55 S9, 2014), centrados en el crédito (Guérin, 2014; James, 2014; Villarreal, 2014), observamos que, más allá del cálculo de intereses mediante instrumentos de mercado -obviamente, dependientes del tiempo (Shipton, 2014)-, el crédito está asimismo vinculado con la evaluación según múltiples valores de aquello que constituye una inversión en un futuro mejor. Las prácticas financieras cotidianas de la gente común suelen tener significados ambivalentes. Las personas pueden pensar en ellas como un activo, cuando sirven para atenuar otras formas de subordinación (por ejemplo, la migración para escapar de la subordinación a un propietario o a un pariente) o para incrementar el propio respeto (por ejemplo, posibilitar gastos ceremoniales o bienes de consumo); aun cuando esta visión obligue a recurrir a un prestamista o a una casa de empeño. Por el contrario, las prácticas financieras pueden ser vistas como una desventaja cuando generan una dependencia mayor que produce vergüenza y cuando llevan a la privación material que lleva al incumplimiento de obligaciones morales. En condiciones precarias, la valoración social suele ser la premisa que sustenta las prácticas de inversión; y el crédito, una herramienta que asume la ambigüedad de proponer un futuro desconocido como medida de las acciones presentes.

Esto conduce nuestra atención hacia el valor social (social worth), como un aspecto central de lo que entendemos por economía. El valor social es el modo en que un sociedad valora a las personas: el valor de las personas, pero también el obtenido a través de las personas y el invertido y acumulado en las personas. Esta perspectiva está inspirada por la teoría antropológica del intercambio, que vincula la acumulación de valor (value) con la valía (worth) personal; así como por una reconfiguración de la teoría del valor-trabajo, que concibe a las personas como el origen de todo el valor incorporado en las mercancías. Finalmente, la riqueza social ("capital social") aparece en todas partes en el centro de las prácticas económicas, enlazada con otras formas de riqueza y su reproducción (Bourdieu, 1980; Granovetter, 1985; para una crítica del concepto de "capital social", ver Narotzky, 2007).

La valía (worth) de las personas se relaciona de manera dialéctica con la forma en que estas se organizan para lograr sostener la vida y, en lo posible, producir una buena vida. Por ejemplo, las jóvenes migrantes malgaches sopesan, por un lado, su valor como proveedoras de cuidados y de trabajo sexual reproductivo a sus maridos franceses $y$, por otro, su valor como proveedoras de recursos para sus familias en su país de origen, que aseguran trabajando como mano de obra barata (Cole, 2014). Cuando las personas pierden su valor (worth), suelen preguntarse: “¿Cómo es posible?”, “¿Cuál fue la causa?”, “¿Quién es responsable?” y “Qué hacer?”. La gente común busca conexiones lógicas y a menudo se focaliza en el poder (ya sea mágico, divino, plutocrático o político) como la fuerza que determina su valor (worth). Y el poder es una relación entre medios y fines definida por su eficacia, que vincula de manera causal entidades humanas y no-humanas. Las conexiones lógicas mediante las cuales las personas entienden estas preguntas frecuentemente se expresan en términos de la responsabilidad que tienen 
los actores sociales en posición de poder de cuidar del resto. Por ejemplo, cuando se piensa que el Estado tiene la responsabilidad de cuidar a las personas, los recortes en las prestaciones sociales son interpretados como un fracaso de aquel en sus obligaciones básicas. Frente a un despido, lo que se plantea es la incapacidad de cuidar que tiene el empresario. En los marcos culturales occidentales -y probablemente en otros también- el cuidado implica dependencia, pero esta debe compensarse con el reconocimiento de autonomía, que es la base de la responsabilidad y de la madurez social y económica. El valor (worth) personal depende de un delicado equilibrio entre ambas (Gallie y Paugam, 2002; Dubois, 2014). Percibido como un tipo de obligación moral basada en el reconocimiento del valor (worth) humano, el cuidado hace que la vida valga la pena, al tiempo que proporciona formas de acceder a recursos (alimentos, vivienda, subsidios, empleo, información, confort, etcétera).

\section{Esperanza}

La economía consiste en proyectar hacia el futuro. Las prácticas económicas de las personas tienen una clara orientación temporal hacia horizontes de expectativas que están enmarcadas tanto por experiencias pasadas como por reconfiguraciones míticas de recuerdos del pasado (por ejemplo, la idealización del pasado cuando "las cosas eran mejores" o la infamia de un pasado "cuando todos pasaron hambre"). Esta orientación temporal puede consistir en aspiraciones individuales que se hacen eco de expectativas preestablecidas, pero que las personas buscan superarlas en pos de una mejora general de las oportunidades de vida. El "sueño americano", por ejemplo, articula una forma de aspiración individual con una configuración colectiva de la esperanza vinculada al bienestar del conjunto de la sociedad y, a la vez, con una forma particular de relaciones de producción y distribución, a saber, históricamente, el fordismo (sobre el utopismo del libre mercado, ver Harvey, 2000, pp. 173-179). Pero el sueño de un futuro mejor puede expresarse de muchas otras maneras. En los modelos económicos dominantes, se expresa como crecimiento y asignación óptima de recursos. En los modelos humanistas, como un florecimiento de las capacidades y del valor (worth) humano (GibsonGraham, 2005; Nelson, 2006; Hart, Laville y Cattani, 2010). En la práctica cotidiana, la gente común traduce estos modelos en proyectos para mejorar la vida de la siguiente generación, aunque claramente lo que se entiende por "mejorar" está condicionado temporal y espacialmente.

En muchas sociedades, las personas equiparan la esperanza de un futuro mejor con el desplazamiento, en la creencia de que la movilidad geográfica puede traducirse en movilidad social, esperando que esta se produzca en la dirección correcta (por ejemplo, Cole, 2014; Palomera, 2014; Pine, 2014; Villarreal, 2014). En estas situaciones, la migración puede entenderse como una proyección material hacia un futuro que se encuentra en otro lugar. Esta proyección material puede adquirir una vida ideacional propia y convertirse en una disposición migratoria que reduce el futuro a la movilidad (Kalir, 2005). Sin embargo, como demuestra Pine (2014), esta disposición puede adquirir diferentes configuraciones en una misma sociedad y en distintos momentos (por ejemplo, las motivaciones para migrar, la perspectiva de regresar, la distribución de responsabilidades). Una disposición migratoria puede florecer incluso frente a una amplia evidencia de que la movilidad no cumple con sus promesas o, peor aún, que puede crear una situación en la que las personas que se desplazan y no "tienen éxito" se ven obligadas a afrontar condiciones de vida muchas veces espantosas, pero que consideran preferibles a la vergüenza de regresar con las manos vacías, como es el caso de las y los migrantes mexicanos en California con quienes trabajó Villarreal (2014). Las personas migrantes pueden desarrollar entre ellas una "economía de apariencias", en la que saben, pero tácitamente acuerdan no comentar, que las historias de éxito que se cuentan unos a otros y a los demás en sus paises de origen adornan la verdad. Este es 
el caso de las mujeres migrantes malgaches, que llevan una vida matrimonial deslucida en la Francia de provincias. Sus narrativas de éxito no se cuestionan cuando vuelven de visita a Madagascar, siempre y cuando se comporten como se espera de una migrante, haciendo exhibición de riqueza y cultivando las relaciones sociales (Cole, 2014). En otras circunstancias, la sensación de "andar sin avanzar" (pattering in place) (Jansen, 2014) o "esperar" (de L'Estoile, 2014) se convierte en una metáfora de las expectativas bloqueadas. Mientras que, en cambio, el "camino a Europa", en el caso de las y los habitantes de Sarajevo, o los proyectos de desarrollo estatales para las y los brasileños de la región nordeste expresan la esperanza de movilidad social individual y colectiva (ver también Ferguson, 1999; Guyer, 2007). Estas dinámicas demuestran tanto el poder como la fragilidad de la ecuación entre esperanza y movimiento.

Entonces, ¿qué es lo que produce un sentido de futuro o su opuesto, de no tener un futuro, del cierre del horizonte de expectativas? ¿Qué tipos de recursos permiten emerger qué futuros? En tanto aspecto de la imaginación, la esperanza constituye un activo importante cuando se carece de recursos materiales en el presente, aunque la completa privación a menudo dificulta la posibilidad de imaginar un futuro. Para Bourdieu (2003), en una situación en que la falta de un futuro es una creciente experiencia para muchos, la relativa autonomía del orden simbólico es la que puede "proporcionar un margen de libertad para una acción política que pueda reabrir el espacio de posibilidades" (p. 336). A su vez, el "utopismo dialéctico" de Harvey apunta a la necesidad de materializar "en realidades institucionales, sociales, culturales y físicas" formas alternativas de imaginar la sociedad que habiliten trayectorias orientadas hacia un futuro mejor (Harvey, 2000, pp. 182-196). La movilización política, por lo tanto, depende de la producción de este margen de libertad, por medio de la materialización de disputas simbólicas que producen nuevos espacios de esperanza. Así, lo que Brodkin (2014) caracteriza adecuadamente como "ciudadanía económica" -para identificar la esperanza de que el trabajo arduo proporcionará seguridad económica, bienestar y respeto básico- es la fuerza de la movilización sindical de trabajadoras y trabajadores auxiliares en un hospital universitario en el sur de los Estados Unidos, y de la movilización medioambiental en las franjas industriales del área metropolitana de Los Ángeles. Esta noción analítica también refleja el reclamo de los campesinos de Guangdong por el reconocimiento del valor de su trabajo y de su identidad social frente al despojo de su tierra por parte de promotores urbanos corruptos y agentes estatales locales (He y Xue, 2014).

En Méditations pascaliennes (Meditaciones pascalianas), Bourdieu (2003) señala que el sentido práctico de futuro de las personas, sus esperanzas de una vida mejor y sus inversiones en términos de una continua acción orientada a un fin están en sintonía con las posibilidades objetivas permitidas por el marco social y económico de su existencia. El habitus aquí es la expresión de los límites que enmarcan las expectativas futuras y que, por lo tanto, condicionan los modos de movilización en el presente, de cara a un futuro. Así, la diferenciación social es incorporada estructuralmente al tiempo que toman forma las expectativas sobre el futuro y las decisiones sobre las inversiones personales. La habilidad práctica para construir el futuro -la capacidad para imaginarlo en el presente- depende de la experiencia material cotidiana de la incertidumbre. Si toda inversión en el futuro está asociada con la incertidumbre, generalmente se entiende que se trata de un espacio de incertidumbre delimitado y regulado por un habitus particular que proporciona un horizonte de expectativas. Esto es lo que Bourdieu (2003) denomina la causalité du probable (causalidad de lo probable; p. 332) según la cual "la voluntad se ajusta a las posibilidades" (p. 312) e incluso puede representarse a través de prácticas contables y dispositivos de cálculo, tales como la hoja de cálculo (Miyazaki, 2006). Sin embargo, la incertidumbre absoluta inhibe la capacidad de producir expectativas cotidianas razonables y expresa la descomposición de la reproducción social y de la economía moral que la sostiene. Por lo tanto, las formas en que las personas se 
apropian de su futuro mediante la movilización política en el presente están estructuralmente ligadas a los límites de la incertidumbre, producidos de forma material por las estructuras económicas y políticas, las instituciones y los actores sociales.

\section{“Gente común”, modelos, métodos etnográficos y escala}

Nuestro enfoque sobre "la gente común" se basa en dos motivaciones relacionadas. Una corresponde al hecho bastante obvio de que las personas cuyas vidas se ven más afectadas por la turbulencia económica del nuevo milenio no son solo las que ocupan la "base de la pirámide" global (Cross y Street, 2009; Errington, Fujikura y Gewertz, 2013), sino también aquellas que antes podían "arreglárselas", a menudo con expectativas de movilidad ascendente. Estas últimas están descubriendo ahora que las prácticas que les habían permitido manejarse en las últimas generaciones son cada vez más esquivas. Estas son las clases medias-bajas, las y los trabajadores pobres, la "clase olvidada" (Newman y Chen, 2008), aquellos que viven con el "miedo a caer" (Ehrenreich, 1990) o, en los términos de moda, "el 99\%". Aquí no estamos siguiendo el giro histórico de la antropología desde el "nicho del salvaje" al "nicho de los sufrientes" (Robbins, 2013). En cambio, estamos centrando nuestra atención en esa amplia base demográfica cuyo declive económico constituye una motivación especialmente impactante para reconsiderar la economía.

La segunda motivación para centrarnos en la gente común remite a una cuestión de importancia tanto teórica como social. En lugar de privilegiar los modelos expertos producidos por economistas y puestos en práctica por Estados y entidades supraestatales, nuestro objetivo es explorar críticamente la relación entre estos modelos y las prácticas económicas en el terreno de aquellas personas cuyo objetivo principal es la búsqueda de su sustento (Narotzky, 2012a). Las y los antropólogos, sociólogos e historiadores han criticado el poder de los modelos expertos y de los dispositivos materiales, sociales y cognitivos que estos despliegan, para producir realidades particulares con las que la gente común debe lidiar (Miller, 1997; Callon, 1998; Carrier y Miller, 1998; Perelman 2000; Mitchell 2002; Elyachar, 2005, 2012). Por ejemplo, las y los responsables de la política económica en Francia elaboran regulaciones que enmarcan la forma en que las y los "funcionarios de ventanilla" de la asistencia social lidiarán con los beneficarios, que siempre se encuentran bajo la sospecha de estar haciendo trampa para recibirla, mientras que, de hecho, solo intentan coordinar sus fuentes de ingresos con las demandas de las economías morales en las que están inmersos. Al mismo tiempo, los modelos expertos que parecen estar orientados hacia la maximización de los recursos sociales del Estado tienen una función moralizadora cada vez más importante, que legitima formas de empleo mal remuneradas y precarias (Dubois, 2014). La crítica que afirma que los modelos expertos están alejados de las realidades cotidianas tiene, por supuesto, una larga genealogía intelectual, que se remonta a la "filosofía de la praxis" de Gramsci y su distinción entre intelectuales tradicionales y orgánicos (Gramsci, 1987) y el poder del discurso hegemónico (Roseberry, 1994).

La perspectiva epistemológica que defendemos se relaciona con la realidad compleja de la esquiva materialidad de los modelos. Primero, éstos son relatos discursivos abstractos que producen una lógica autorizada de causalidad. En segundo lugar, los modelos económicos son representaciones formales (matemáticas) de modelos discursivos que enmascaran sus objetivos políticos bajo la formalidad técnica. En tercer lugar, son instrumentos para el ejercicio del poder. En resumen, los modelos son intentos de controlar una realidad desordenada mediante la abstracción: el control a partir de la producción de conocimiento y del dominio epistémico, y el control de la acción humana a partir de la fuerza performativa, no solo de los diseños en sí, sino también de las relaciones que estos privilegian. Los modelos producen un contexto ideológico 
que canaliza la acción hacia la continuidad de formas de diferenciación particulares. Se los puede considerar como dispositivos que encarnan la hegemonía (Williams, 1977) o que producen habitus, tanto en la práctica académica, como en la vida cotidiana (Bourdieu, 2003). Aunque se presentan como descripciones de la realidad observada, sin embargo, son proyectos que diseñan el futuro a partir de una combinación de memorias de experiencias pasadas e imaginación intencional. El concepto de "economización" proporciona una oportunidad prometedora para analizar la forma en que los modelos y las realidades económicas se entrelazan, ya que reúne los procesos (comportamientos, instituciones, dispositivos materiales, etc.) que configuran lo que tanto las y los académicos como la gente común realizan como "económico". Este concepto asume que la economía no preexiste a la acción económica, sino más bien, está constituida por esta última (Çalişkan y Callon, 2009, 2010). Sin embargo, más allá de la economización, el diseño de modelos económicos -ya sean expertos o populares- es el efecto de luchas políticas en que las relaciones de poder son efectuadas, y que resultan en la producción de diferencias que limitan las oportunidades de las personas para ganarse la vida.

La metodología más adecuada para una investigación con estas complejidades es la etnografía. Esta permite explorar cómo se construyen los modelos y los procesos mediante los que algunos de ellos son investidos de autoridad, y otros no. También nos permite explorar cómo las personas pueden socavar o evitar los modelos hegemónicos en la orientación de sus vidas. La etnografía ayuda a captar la creación de los modelos en su realidad cotidiana, así como sus ramificaciones, a partir de lo que se define como "económico", para abarcar lo social, el dominio privado de los hogares y las familias, la cultura de las corporaciones, el taller, el sindicato, la movilización social y el debate académico. La etnografía aborda los modelos como espacios de lucha por definir lo que se considera relevante. La comparación etnográfica juega un papel crucial, porque permite encarar el hecho de que los modelos son objetos abstractos separables, capaces de circular a lo largo de paisajes geográficos, sociales y culturales, pero, al mismo tiempo, ejerciendo su poder solo en tanto manifestaciones concretas y únicas de realidades históricas, sociales y culturales.

Este compromiso con la vida tal como es vivida expone el poder variable de los modelos y su relación con la vida cotidiana, en particular las tensiones que surgen en el diseño y la actualización de los modelos a diferentes escalas. Tal es el caso, por ejemplo, del análisis de Dubois (2014) acerca de la brecha fundamental entre el diseño de las políticas de bienestar francesas, la puesta en acto de estas políticas durante las entrevistas de control a los destinatarios y los usos pragmáticos de los beneficios sociales en la vida cotidiana de las y los beneficiarios de ellas. Los modelos también pueden enfrentarse entre sí en contextos nacionales inverosímilmente distantes, cuando debates sobre políticas en un país luego afectan la vida local de las y los ciudadanos comunes en otro. Por ejemplo, como resultado del ingreso de China a la Organización Mundial del Comercio (OMC) en 2001, las industrias rurales y las pequeñas empresas en Europa se vieron afectadas por un debate técnico entre políticos y economistas sobre cómo definir la economía china (como una economía de mercado o de no mercado) y sobre cómo calcular el valor de sus mercancías, a fin de decidir si sus prácticas de exportación eran equitativas o no. A nivel local, trabajadores, pequeños empresarios y representantes de grandes firmas industriales y comerciales plantearon distintas definiciones acerca de las dinámicas globales en juego, al calificar de "dumping" lo que otros definieron como importaciones baratas, y pedir medidas proteccionistas a nivel estatal y de la Unión Europea (Narotzky, 2009; véase también Neiburg, 2011, para las luchas en torno a los índices de inflación en Brasil, y He y Xue, 2014). Etnografías de las regiones socialistas y postsocialistas han proporcionado perspectivas especialmente ricas sobre las tensiones producidas a distintas escalas, tanto por la aplicación de los modelos, como por las luchas en torno a sus definiciones locales (Verdery, 1996; Burawoy y Verdery, 1999; Humphrey, 2002; Mandel y Humphrey, 2002), como demuestran de manera vívida 
Pine (2014) y Jansen (2014) con materiales etnográficos del período postsocialista en Polonia y Bosnia.

En las etnografías, los problemas de escala emergen en situaciones en las que la gente común experimenta sus oportunidades de vida como pertenecientes, simultáneamente, a varios dominios de la práctica. Un ejemplo de ello son las personas que suministran alimentos como dote matrimonial, al tiempo que consolidan relaciones de intercambio con sus aliados y reproducen su alianza cosmológica con sus ancestros y sus tierras (Malinowski, 1935). Cuando un joven es empujado a emigrar como trabajador no cualificado, o como un aspirante a atleta (por el Estado, por su familia o por su deseo de "lograrlo"), se está comprometiendo con las oportunidades materiales y los marcos morales tanto del mercado laboral internacional (o regional), como de los recursos y prioridades de su comunidad, de los recursos y expectativas de su familia, y de sus capacidades y deseos personales (Besnier, 2012). Estas diferentes escalas se conforman mutuamente de manera continua, aunque también adquieren una relativa estabilidad mediante dispositivos institucionales y técnicos. No existe una lógica global trascendental que pueda explicar las prácticas económicas a nivel micro o macro, como lo hacen los modelos neoclásicos de mercado. Lo mejor que podemos hacer probablemente sea observar de modo analítico cómo se definen las diversas escalas y cómo se articulan en la práctica (Swyngedouw, 2004).

Las relaciones económicas contemporáneas participan simultáneamente en múltiples escalas de valor y marcos institucionales. Esta simultaneidad a menudo crea entornos complejos y contradictorios en los que las personas emiten juicios sobre lo que pueden $o$ deben hacer para ganarse la vida. Estos juicios pueden ser informados por obligaciones morales en conflicto entre los actores sociales y pueden conllevar muy distintos tipos de acción. La importancia y el entrelazamiento de economías diversas en el mundo real exige romper la camisa de fuerza conceptual que las ha distanciado y definido como fenómenos separados, destacando algunas y marginando a otras (Escobar, 2004; Gibson-Graham, 2005, 2014; de Sousa Santos, 2006). Si bien el pluralismo económico es importante, la coemergencia y la interacción de estas economías "diversas" son igualmente importantes. Como han acentuado las teorías marxistas de la articulación y la dependencia, la diferencia es producida dialécticamente en el marco de estructuras de poder que atraviesan distintas escalas (Wolpe, 1980).

\section{Crisis, valor y esperanza: repensando la economía}

Los artículos reunidos en el dossier especial de Current Anthropology (Vol. 55, S9, 2014) fueron desarrollados a partir de escritos originalmente presentados en el Simposio Internacional de Wenner-Gren "Crisis, valor y expectativas: repensando la economía", que tuvo lugar en Sintra, Portugal, entre el 14 y 20 de septiembre de 2012. Se refieren a muchas cuestiones que reúnen los tres temas de crisis, valor y esperanza en torno a la evaluación del valor (value) y de la valía (worth) de las personas. Exploran los modos en que la dimensión práctica de hacer malabarismos con diversos regímenes de valor involucra no solo las transacciones y la circulación de valor, sino también la creación y mantenimiento de relaciones sociales y la emergencia de identidades sociales particulares, que son recursos cruciales en tiempos de necesidad. La producción y circulación de recursos y los desplazamientos entre los diferentes campos de valor afectan las relaciones sociales, y las identidades emergen en el contexto de las relaciones sociales creadas por estos procesos. Los actores sociales, situados diferencialmente, utilizarán diversos tipos de racionalidades para acceder a los recursos y utilizarlos. A menudo, estas diferentes lógicas entran en conflicto entre sí. En otros momentos, emociones como la vergüenza actúan como reguladores de la dinámica material y social. 
La capacidad para acceder a diferentes tipos de recursos valiosos está íntimamente relacionada con la temporalidad, particularmente cuando la relación entre el presente y el futuro está cargada de incertidumbre. Pero esta temporalidad puede complicarse, ya que las certezas de futuro que las personas tenían en el pasado pueden convertirse en la vara para medir las incertidumbres experimentadas por las personas en el presente. Pasado, presente y futuro están relacionados entre sí de múltiples maneras en los modos en que las personas comprenden sus experiencias y en sus definiciones de proyectos para el futuro. Al mismo tiempo, diferentes temporalidades interactúan entre sí y en la evaluación de los valores conferidos por las personas a los diferentes recursos y a los canales que los vehiculan. ¿Qué efectos tiene la incertidumbre radical sobre los medios de vida en las prácticas cotidianas de las personas para ganarse la vida?

En aquellas regiones del mundo donde los actores sociales creen que la movilidad geográfica se traducirá en movilidad socioeconómica, múltiples tipos de evaluación están implicados en las decisiones de migrar o quedarse. Diferentes regímenes de valor operan en esta toma de decisiones y en las nuevas relaciones sociales y económicas generadas por la movilidad. La esperanza proporciona un horizonte para la experiencia de la movilidad geográfica, y para la movilidad socioeconómica que se espera que esta genere. Las esperanzas frustradas y la vergüenza operan, a veces, como un obstáculo para la movilidad y pueden agravar el sentimiento de crisis y de falta de valor, de inutilidad (worthlessness). Pero la inmovilidad también puede ser la metáfora de una incertidumbre radical que inhibe la proyección a futuro.

Un principio clásico de la economía política es que los distintos grupos asignan un valor diferente a su contribución en la producción. Estas diferencias están en la raíz de la desigualdad y están íntimamente ligadas a las condiciones de inseguridad de aquellos cuyo valor social (worth) no es reconocido. Al mismo tiempo, estas diferencias pueden ser puestas en funcionamiento y pueden establecer el marco para el conflicto y la mobilización, que puede ser colectiva, individual o intermediada por terceros como activistas laborales, intermediarios empresariales u organizadores sindicales. La incertidumbre, entonces, puede transformarse en un proyecto para el futuro y motivar a las personas a movilizarse con ese fin. A veces, el no reconocimiento se convierte en el fundamento de la acción política, aunque esto no siempre es así. La movilización para conseguir el reconocimiento o para reclamar recursos o derechos descansa sobre formas particulares de identificación y crea otras que no existían anteriormente.

Finalmente, el valor constituye el eje del poder institucional, ya que éstas se basan en la definición de límites en torno a lo que constituye valor (value) y quién es valioso (worthy). La reproducción social se estabiliza y regula mediante la definición de dichos límites, que producen continuidad en los patrones de distribución de recursos y de valor social (social worth). En tiempos de crisis, las instituciones y sus relaciones con la ciudadanía se reconfiguran, y con frecuencia toman éstas la forma de juicios acerca de la moralidad de personas particulares, de sus estatus o sus acciones. Por lo tanto, los momentos de crisis resultan en el realineamiento de las instituciones y de las relaciones de sus agentes con la gente común. La capacidad de la gente común para reconfigurar o sortear el poder formalizador de las instituciones en su búsqueda de un futuro mejor es una forma de lucha dirigida a redefinir las formas de responsabilidad política y de obligación moral de los poderosos.

Ganarse la vida consiste en "producir personas" en sus dimensiones físicas, sociales, espirituales, afectivas e intelectuales. Consiste en las formas de interacción humana que hacen que diferentes tipos de recursos estén disponibles -aunque a menudo de manera desigual- a través de las relaciones sociales de producción, distribución y consumo. Consiste en las luchas y la estabilización en torno al valor social (worth) de las personas 
y a cómo hacer que la vida valga la pena de ser vivida. Es este esfuerzo por producir vida lo que llamamos "economía".

\section{Sobre los autores}

Susana Narotzky es Catedrática de la Universidad de Barcelona. Es Doctora en Ciencias Sociales y Políticas (New School Social Research, NY) y Doctora en Historia y Geografía (con orientación en antropología) por la Universidad de Barcelona. Ha dirigido el ERC Grassroots Economics: Meaning, Project and practice in the pursuit of livelihood. Entre 2019 y 2020 ha sido investigadora invitada del Social Science School, Institute for Advanced Study, Princeton con el tema "Valuations of life: struggling for a future in Southern Europe". Sus temas de investigación giran en torno a la antropología económica, las relaciones de género, los modelos económicos, los procesos de crisis así como en la relación entre memoria y producción de la agencia política

Niko Besnier es Profesor de Antropología Cultural de la University of Amsterdam e investigador Honorario del Departamento de Investigación Social en La Trobe, Melbourne. Realizó su doctorado en lingüística en la University of Southern California Entre 2016 y 2019 fue Editor en Jefe de American Ethnologist y entre 2019-2020 Fellow en el Helsinki Collegium for Advanced Studies. Se ha especializado en temas relativos a la Antropología de la globalización, género, sexualidad, deporte, movilidad y lenguaje.

\section{Financiamiento}

Susana Narotzky recibió financiamiento del European Research Council, Advanced Grant 2012 para el proyecto "Grassroots Economics: Meaning, Project and Practice in the Pursuit of Livelihood" [GRECO], Project Number: 323743 (2013-2019). También de la Beca ICREA-Academia (2011-2015) de la Generalitat de Catalunya, y la subvención (CSO2011-26843) del Ministerio de Economía y Competitividad de España.

Niko Besnier recibió financiamiento del European Research Council Advanced Grant Proyecto para el proyecto "Globalization, Sport and the Precarity of Masculinity" [GLOBALSPORT], Proyect Number: 295769 (2012-17).

\section{Agradecimientos}

Agradecemos a la Fundación Wenner-Gren, particularmente a Leslie Aiello y Laurie Obbink, por la financiación y la organización del Simposio de Sintra y a cada uno de los participantes por los valiosos aportes realizados. Entre ellos, a las y los autores de los artículos del número especial de Current Anthropology (Vol. 55, S9, 2014) y a Stephen Gudeman, Gavin Smith y Janet Roitman. Además, queremos agradecer a los seis revisores anónimos por los útiles comentarios que hicieron posible esta publicación. 


\section{Q Referencias bibliográficas}

》Albert, E. M. (1956). The classification of values: a method and illustration. American Anthropologist, 58, 221-248.

"Appadurai, A. (1988a). Introduction: commodities and the politics of value. En The social life of things: commodities in cultural perspective (pp. 3-63). Cambridge: Cambridge University Press.

" Appadurai, A. (Ed.). (1988b). The social life of things: commodities in cultural perspective. Cambridge: Cambridge University Press.

"Benería, L. (2003). Gender, development and globalization. Londres: Routledge.

» Besnier, N. (2009). Modernity, cosmopolitanism, and the emergence of middle class in Tonga. Contemporary Pacific, 21, 215-262.

"Besnier, N. (2011). On the edge of the global: modern anxieties in a Pacific Island nation. Stanford: Stanford University Press.

" Besnier, N. (2012). The athlete's body and the global condition: Tongan rugby players in Japan. American Ethnologist, 39, 491-510.

" Blim, M. (1990). Made in Italy: small-scale industrialization and its consequences. Nueva York: Praeger.

" Bloch, M. y Parry, J. (1989). Introduction: Money and the morality of exchange. En Money and the morality of exchange (pp. 1-32). Cambridge: Cambridge University Press.

» Bohannan, P. (1959). The impact of money on an African subsistence economy. Journal of Economic History, 19, 491-503.

" Bourdieu, P. (1980). Le capital social: notes provisoires. Actes de la Recherche en Sciences Sociales, 31, 2-3.

》 Bourdieu, P. (2003). Méditations pascaliennes. Edición revisada. París: Seuil.

" Brandtstädter, S. (2003). With Elias in China: civilizing process, local restorations and power in contemporary rural China. Anthropological Theory, 3, 87-105.

» Brodkin, K. (2014). Work, race, and economic citizenship. Current Anthropology, 55(9), 116125 .

"Browne, K. E. (2009). Economics and morality: Introduction. En K. E. Browne y B. Lynne Milgram (Eds.), Economics and morality: anthropological approaches (pp. 1-40). Lanham: Altamira.

" Burawoy, M. y Verdery, K. (1999). Uncertain transition: ethnographies of change in the postsocialist world. Oxford: Rowman \& Littlefield.

» Çali kan, K. y Callon, M. (2009). Economization. 1. Shifting attention from the economy towards processes of economization. Economy and Society, 38, 369-398.

» Çali kan, K. y Callon, M. (2010). Economization. 2. A research programme for the study of markets. Economy and Society, 39, 1-32.

"Callon, M. (1998). An essay on framing and overflowing: economic externalities revisited by sociology. En The laws of the markets (pp. 244-269). Oxford: Blackwell.

"Carrier, J. y Miller, D. (1998). Virtualism: a new political economy. Oxford: Berg. 
»Cole, J. (2014). Producing value among Malagasy marriage migrants in France: managing horizons of expectation. Current Anthropology, 55(9), 85-94.

»Cross, J. y Street, A. (2009). Anthropology at the bottom of the pyramid. Anthropology Today, 25(4), 4-9.

»Dalla Costa, M. y James, S. (1975). El poder de la mujer y la subversión de la comunidad. Ciudad de México: Siglo XXI.

» Damon, F. H. (1980). The Kula and generalised exchange: considering some unconsidered aspects of the elementary structures of kinship. Man, 15(2), 267-292.

»De L'Estoile, B. (2014). "Money is good, but a friend is better": uncertainty, orientation to the future, and the economy. Current Anthropology, 55(9), 62-73.

" de Sousa Santos, Boaventura. (2006). Another production is possible. London: Verso

»Dubois, V. (2014). The economic vulgate of welfare reform: elements for a socioanthropological critique. Current Anthropology, 55(9), 138-146.

»Edelman, M. (2005). Bringing the moral economy back in... to the study of 21st-century transnational peasant movements. American Anthropologist, 107, 331-345.

» Ehrenreich, B. (1990). Fear offalling: the inner life of the middle class. Nueva York: Harper.

» Elson, D. (2001, septiembre). For an emancipatory socio-economics. En United Nations Research Institute for Social Development meeting on The Need to Rethink Development Economics. Instituto de Investigación de las Naciones Unidas para el Desarrollo Social. Cape Town.

» Elyachar, J. (2005). Markets of dispossession: NGOs, economic development, and the state in Cairo. Durham: Duke University Press.

»Elyachar, J. (2012). Before (and after) neoliberalism: tacit knowledge, secrets of the trade, and the public sector. Cultural Anthropology 27, 76-96.

» Errington, F., Fujikura, T. y Gewertz, D. (2013). The noodle narratives: the global rise of an industrial food into the twenty-first century. Berkeley: University of California Press.

»Escobar, A. (2004). Beyond the third world: imperial globality, global coloniality and anti-globalisation social movements. Third World Quarterly, 25, 207-230.

»Fassin, D. (2009). Les économies morales revisitées. Annales: Histoire, Sciences Sociales, $64,1237-1266$.

» Ferber, M. A. y Nelson, J. (1993). Beyond economic man: feminist theory and economics. Chicago: University of Chicago Press.

» Ferber, M. A. y Nelson, J. (2003). Feminist economics today: beyond economic man. Chicago: University of Chicago Press.

» Ferguson, J. (1999). Expectations of modernity: myths and meanings of urban life on the Zambian Copperbelt. Berkeley: University of California Press.

» Fontaine, L. (2008). L'économie morale: pauvreté, crédit et confiance dans l'Europe préindustrielle. París: Gallimard.

» Funtowicz, S. O. y Ravetz, J. R. (1994). The worth of a songbird: ecological economics as a post-normal science. Ecological Economics, 10, 197-207.

» Gallie, D. y Paugam, S. (2002). Social precarity and social integration: report for the European Commission based on Eurobarometer 56.1. Bruselas: European Commission.

» Gibson-Graham, J. K. (2005). A postcapitalist politics. Minneapolis: University of Minnesota Press. 
" Gibson-Graham, J. K. (2014). Rethinking the economy with thick description and weak theory. Current Anthropology, 55(9), 147-153.

» Gingrich, A. (2006). Neo-nationalism and the reconfiguration of Europe. Social Anthropology, 14, 195-217.

» Godelier, M. (1996). L'énigme du don. París: Fayard.

" Graeber, D. (2001). Toward an anthropological theory of value: the false coin of our own dreams. Nueva York: Palgrave.

» Graeber, D.(2011). Debt: the first 5,0oo years. Brooklyn, NY: Melville House.

» Gramsci, A. (1987 [1929-1935]). Selections from the prison notebooks. Nueva York: International.

»Granovetter, M. (1985). Economic action and social structure: the problem of embeddedness. American Journal of Sociology, 91, 481-510.

» Gregory, C. (1982). Gifts and commodities. Cambridge: Cambridge University Press.

» Gregory, C. (1997). Savage money: the anthropology and politics of commodity exchange. Ámsterdam: Harwood Academic.

" Gudeman, S. (2008). Economy's tension: the dialectics of community and market. Nueva York: Berghahn.

»Guérin, I. (2014). Juggling with debt, social ties, and values: the everyday use of microcredit in rural South India. Current Anthropology 55(9), 40-50.

» Guyer, J. (2004). Marginal gains: monetary transactions in Atlantic Africa. Chicago: University of Chicago Press.

» Guyer, J. (2007). Prophecy and the near future: thoughts on macroeconomic, evangelical, and punctuated time. American Ethnologist, 34(3), 409-421.

» Hage, G. (1998). White nation: fantasies of white supremacy in a multicultural society. Londres: Taylor \& Francis.

» Hann, C. (2010). Moral economy. En K. Hart, J. L. Laville y A. D. Cattani (Eds.), The human economy (pp. 187-198). Oxford: Polity.

» Hareven, T. (1977). Family time and industrial time: family and work in a planned corporation town, 1900-1924. En Family and kin in urban communities, 1700-1930 (pp. 187-207). Nueva York: New Viewpoints.

» Hart, K. (1973). Informal income opportunities and urban employment in Ghana. Journal of Modern African Studies, 11, 61-89.

» Hart, K. (2000). The memory bank: money in an unequal world. Londres: Profile.

» Hart, J. L. Laville y A. D. Cattani (Eds.). (2010). The human economy. Oxford: Polity.

» Hartmann, H. (1981). The family as the locus of gender, class, and political struggle: the example of housework. Signs, 6, 366-394.

» Harvey, D. (2000). Spaces of hope. Berkeley: University of California Press.

» Harvey, D. (2003). The new imperialism. Oxford: Oxford University Press.

» He, S. y Xue, D. (2014). Identity building and communal resistance against landgrabs in Wukan Village, China. Current Anthropology, 55(9), 126-137.

» Hochschild, A. R. (2003). Commercialization of intimate life: notes from home and work. Berkeley: University of California Press. 
" Holmes, D. R. (2000). Integral Europe: fast-capitalism, multiculturalism, neofascism. Princeton: Princeton University Press.

" Hondagneu-Sotelo, P. (2001). Doméstica: immigrant workers cleaning and caring in the shadows of affluence. Berkeley: University of California Press.

» Humphrey, C. (2002). The unmaking of Soviet life: everyday economies after socialism. Ithaca: Cornell University Press.

"James, D. (2014). "Deeper into a hole?" borrowing and lending in South Africa. Current Anthropology, 55(9), 17-29.

" Jansen, S. (2014). On not moving well enough: temporal reasoning in Sarajevo yearnings for "normal lives". Current Anthropology, 55(9), 74-84.

» Kalb, D. (2009). Conversations with a Polish populist: tracing hidden histories of globalization, class, and dispossession in postsocialism (and beyond). American Ethnologist, 36, 207-223.

» Kalir, B. (2005). The development of a migratory disposition: explaining a "new emigration". International Migration, 43, 167-196.

" Koselleck, R. (2006). Crisis. Journal of the History of Ideas, 67, 357-400.

"Lawson, V. (2007). Geographies of care and responsibility. Annals of the Association of American Geographers, 97, 1-11.

" Li, T. M. (2001). Relational histories and the production of difference on Sulawesi's upland frontier. Journal of Asian Studies, 60, 41-66.

》 Lomnitz, L. (1975). Cómo sobreviven los marginados. Ciudad de México: Siglo XXI.

» Malinowski, B. (1935). Coral gardens and their magic: soil-tilling and agricultural rites in the Trobriand Islands. Londres: Allen \& Unwin.

"Malinowski, B. (1961a). Argonauts of the western Pacific. Nueva York: Dutton.

"Malinowski, B. (1961b). Crime and custom in savage society. Londres: Routledge \& Kegan Paul.

" Mandel, R. y Humphrey C. (Eds.) (2002). Markets and moralities: ethnographies of postsocialism. Oxford: Berg.

» Martínez-Alier, J., Monda, G. y O'Neill, J. 1998. Weak comparability of values as a foundation for ecological economics. Ecological Economics, 26, 277-286.

"Marx, K. (1990). Capital: A critique of political economy (Vol. 1). Harmondsworth: Penguin.

» Maurer, B. (2006). The anthropology of money. Annual Review of Anthropology, 35, 15-36.

» Mauss, M. (2003). Essai sur le don. Forme et raison de l'échange dans les sociétés archaïques. En Sociologie et anthropologie. (pp. 145-279) París: Presses Universitaires de France.

" McDowell, L. (2004). Work, workfare, work/life balance and an ethic of care. Progress in Human Geography, 28(2), 145-163.

》 Miller, D. (1997). Capitalism: an ethnographic approach. Oxford: Berg.

" Mintz, S.W. (1986). Sweetness and power: the place of sugar in modern history. Nueva York: Penguin.

》 Mitchell, T. (2002). Rule of experts. Berkeley: University of California Press.

» Miyazaki, H. (2006). Economy of dreams: hope in global capitalism and its critiques. Cultural Anthropology, 21, 147-172. 
》 Moore, B. (1978). Injustice: the social bases of obedience and revolt. Nueva York: MacmiIlan.

» Munch, P. A. (1970). Economic development and conflicting values: a social experiment in Tristan da Cunha. American Anthropologist, 72, 1300-1318.

» Munn, N. D. (1992). The fame of Gawa: a symbolic study of value transformation in a Massim (Papua New Guinea) society. Durham: Duke University Press.

» Narotzky, S. (1988). Trabajar en familia: mujeres, hogares y talleres. Valencia: Alfons el Magnánim.

»Narotzky, S. (2007). The project in the model: reciprocity, social capital, and the politics of ethnographic realism. Current Anthropology, 48, 403-424.

" Narotzky, S. (2009). Regulation and production in a globalized world: what ethnography brings to comparison. Ethnology, 48, 175-193.

» Narotzky, S. (2012a). Europe in crisis: grassroots economies and the anthropological turn. Etnográfica, 16, 627-638.

»Narotzky, S. (2012b). Provisioning. En J. Carrier (editor). A handbook of economic anthropology. 2da. ed. (pp. 78-93). Cheltenham: Elgar.

» Neiburg, F. (2011). La guerre des indices. L'inflation au Brésil (1964-1994). Genéses, 84, $25-46$.

» Nelson, J. A. (2006). Economics for humans. Chicago: University of Chicago Press.

» Newman, K. y Tan Chen, V. (2008). The missing class: portraits of the near poor in America. Boston: Beacon.

» Owusu, F. (2008). Conceptualizing livelihood strategies in African cities: planning and development implications of multiple livelihood strategies. Journal of Planning Education and Research, 26, 450-465.

»Palomera, J. (2014). Reciprocity, commodification, and poverty in the era of financialization. Current Anthropology, 55(9), 105-115.

» Parrenãs, R. S. (2001). Servants of globalization: women, migration and domestic work. Stanford: Stanford University Press.

»Perelman, M. (2000). The invention of capitalism: classical political economy and the secret history of primitive accumulation. Durham: Duke University Press.

» Pine, F. (2014). Migration as hope: space, time, and imagining the future. Current Anthropology, 55(9), 95-104.

"Polanyi, K. (1971). The great transformation. Boston: Beacon.

"Portes, A. y Sensenbrenner, J. (1993). Embeddedness and immigration: notes on the social determinants of economic action. American Journal of Sociology, 98, 1320-1350.

»Procoli, A. (Ed.) (2004). Workers and narratives of survival in Europe. Albany: State University of Nueva York Press.

" Razavi, S. (2007). The political and social economy of care in a development context: conceptual issues, research questions and policy options. Geneva: United Nations Research Institute for Social Development.

»Robbins, J. (2009). Rethinking gifts and commodities: reciprocity, recognition, and the morality of exchange. En K. Browne y L. B. Milgram (Eds.), Economics and morality: anthropological approaches (pp. 43-58). Lanham: Altamira. 
" Robbins, J. (2013). Beyond the suffering subject: toward an anthropology of the good. Journal of the Royal Anthropological Institute, 19, 447-462.

» Robbins, J. y Akin, D. (Eds.). (1999). An introduction to Melanesian currencies: agency, identity, and social reproduction. En Money and modernity: state and local currencies in Melanesia (pp. 1-40). Pittsburgh: University of Pittsburgh Press.

"Roseberry, W. (1988). Political economy. Annual Review of Anthropology, 17, 161-185.

" Roseberry, W. (1989). Anthropologies and histories: essays in culture, history and political economy. New Brunswick: Rutgers University Press.

" Roseberry, W.(1994). Hegemony and the language of contention. En G. M. Joseph y D. Nugent (Eds.), Everyday forms of state formation: revolution and the negotiation of rule in modern Mexico (pp. 355-366). Durham: Duke University Press.

"Sayer, A. (2000). Moral economy and political economy. Studies in Political Economy, 61, 79-103.

» Scott, J. C. (1976). The moral economy of the peasant: rebellion and subsistence in Southeast Asia. New Haven: Yale University Press.

"Shipton, P. (2014). Trusting and transcending: sacrifice at the source of the Nile. Current Anthropology, 55(9), S51-S61.

" Sider, G. (1996). Cleansing history: Lawrence, Massachusetts, the strike for four loaves of bread and no roses, and the anthropology of working-class consciousness. Radical History Review, 65, 48-83.

»Smart, A, y Smart, J. (Eds.). (2005). Petty capitalists and globalization: flexibility, entrepreneurship, and economic development. Albany: State University of Nueva York Press.

"Smart, J. y Smart, A. (1993). Obligation and control: employment of kin in capitalist labour management in China. Critique of Anthropology, 13, 7-31.

» Smith, G. (2011). Selective hegemony and beyond: populations with "no productive function": a framework for enquiry. Identities, 18, 2-38.

»Spash, C. L. (2000). Multiple value expression in contingent valuation: economics and ethics. Environmental Science and Technology, 34, 1433-1438.

»Spooner, B. (1988). Weavers and dealers: the authenticity of an oriental carpet. En A. Appadurai (Ed.), The social life of things: commodities in cultural perspective (pp. 195-235). Cambridge: Cambridge University Press.

"Stack, C. (1974). All our kin: strategies for survival in a black community. Nueva York: Harper \& Row.

"Strathern, M. (1988). The gender in the gift: problems with women and problems with society in Melanesia. Berkeley: University of California Press.

"Strathern, M. (1992). Qualified value: the perspective of gift exchange. En C. Humphrey y S. Hugh-Jones (Eds.), Barter, exchange and value (pp. 169-190). Cambridge: Cambridge University Press.

"Swyngedouw, E. (2004). Globalisation or "glocalisation"? Networks, territories and rescaling. Cambridge Review of International Affairs, 17, 25-48.

» Terradas, I. (1992). Eliza Kendall: reflexiones sobre una antibiografía. Bellaterra: Publicacions de la Universitat Autònoma de Barcelona.

» Thomas, N. (1991). Entangled objects: exchange, material culture, and colonialism in the Pacific. Cambridge: Harvard University Press. 
" Thompson, E. P. (1971). The moral economy of the English crowd in the eighteenth century. Past and Present, 50, 76-136.

» Thompson, E. P. (1993). The moral economy reviewed. En Customs in common (pp. 259351). Nueva York: New Press.

»Verdery, K. (1996). What was socialism, and what comes next? Princeton: Princeton University Press.

» Villarreal, M. (2014). Regimes of value in Mexican household financial practices. Current Anthropology, 55(9), S30-S39.

» Weber, F, Gojard, S. y Gramain, A. (Eds.) (2003). Charges de famille. Dépendance et parenté dans la France contemporaine. París: La Découverte.

»Weiner, A. B. (1980). Reproduction: a replacement for reciprocity. American Ethnologist, 7, 71-85.

"Weiner, A. B. (1992). Inalienable possessions: the paradox of keeping-while-giving. Berkeley: University of California Press.

»West, P. (2005). Translation, value, and space: theorizing an ethnographic and engaged environmental anthropology. American Anthropologist, 107, 632-642.

»Williams, R. (1977). Marxism and literature. Oxford: Oxford University Press.

»Wolf, E. R. (1982). Europe and the people without history. Berkeley: University of California Press.

» Wolf, E. R. (1999). Envisioning power: ideologies of dominance and crisis. Berkeley: University of California Press.

» Wolpe, H. (Ed.) (1980). The articulation of modes of production. Londres: Routledge \& Kegan Paul.

»Yanagisako, S. (2002). Producing culture and capital: family firms in Italy. Princeton: Princeton University Press.

» Yeates, N. (2004). Global care chains. International Feminist Journal of Politics, 6, 369-391.

»Zelizer, V. (1997). The social meaning of money: pin money, paychecks, poor relief, and other currencies. Princeton, Princeton University Press. 